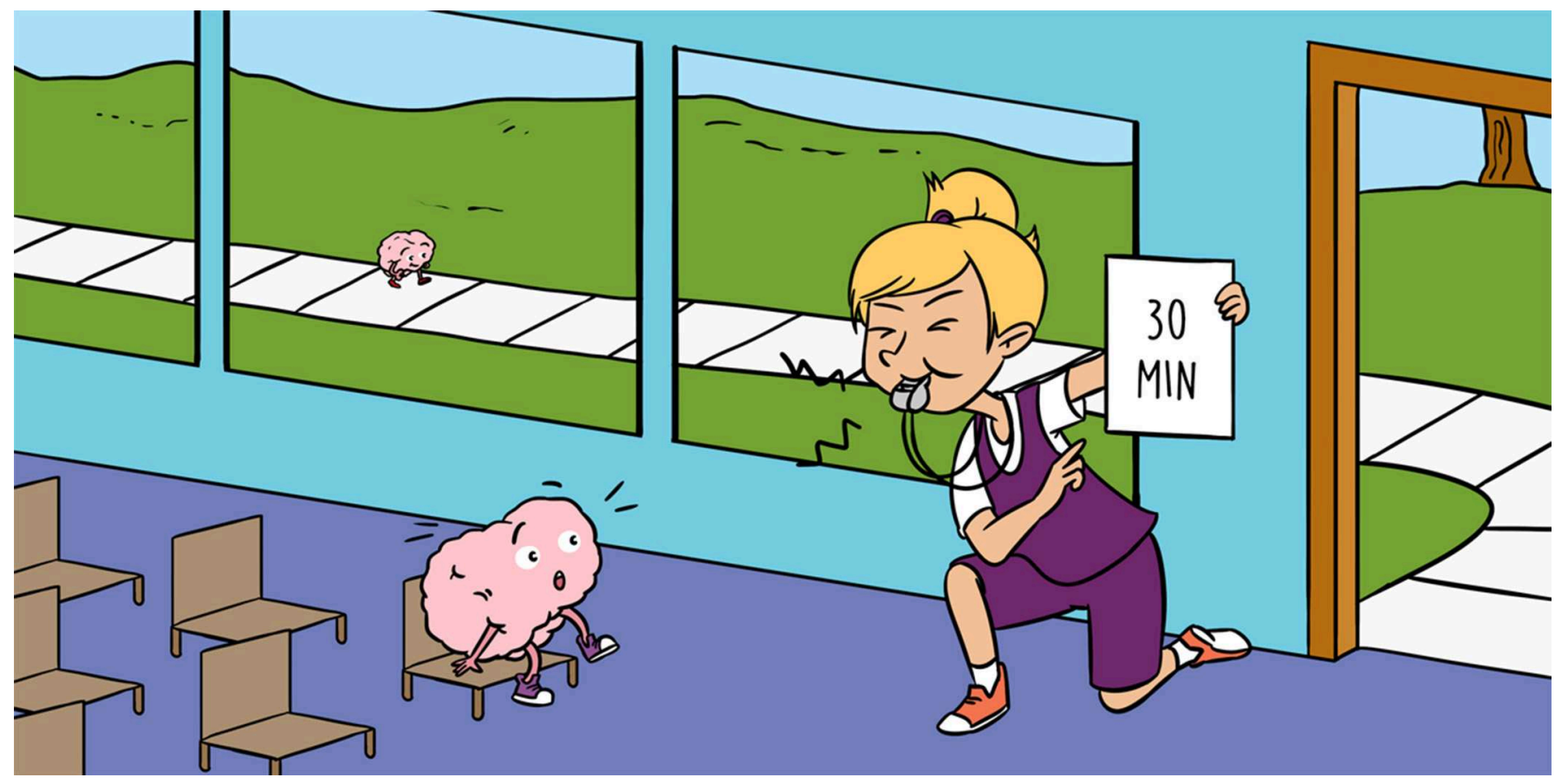

\title{
TAKING REGULAR BREAKS FROM SITTING PREVENTS REDUCTIONS IN BRAIN BLOOD FLOW
}

\section{Sophie E. Carter ${ }^{1,2^{*}}$, Sophie M. Holder ${ }^{1}$, Dick H. J. Thijssen ${ }^{1,3}$ and Nicola D. Hopkins ${ }^{1}$}

${ }^{1}$ Research Institute for Sport and Exercise Sciences, Liverpool John Moores University, Liverpool, United Kingdom

${ }^{2}$ School of Sport, York St. John University, York, United Kingdom

${ }^{3}$ Department of Physiology, Radboud Institute for Health Sciences, Radboud University Medical Center, Nijmegen, Netherlands

\section{YOUNG REVIEWERS:}

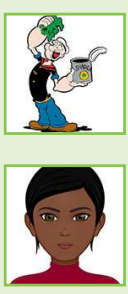

ANEAL

AGE: 15

JEANINE

AGE: 14

Supplying the brain with enough blood flow is essential to keep us alive and maintain our brain health. Reductions in brain blood flow 


\section{COGNITION}

The mental processes by which we think, understand, pay attention, solve problems, learn and remember information.

\section{DEMENTIA}

A condition that causes memory loss and confusion, and changes how a person acts.

\section{SEDENTARY}

\section{BEHAVIOR}

Is any activity while a person is awake, when they are in a sitting, reclining or lying position and using a low amount of energy.

\section{BRAIN BLOOD FLOW: WHY IS IT IMPORTANT?}

Blood supplies the brain with the oxygen and nutrients it needs to carry out its everyday tasks. Providing enough blood to the brain is therefore essential for the brain to be able to function and to keep us alive. Over a short time period, decreases in the amount of blood flowing to the brain can reduce cognition [1], which involves the mental processes that allow us to think, understand, and learn information. Reductions in blood flow to the brain that occur over a long time period may lead to diseases, such as dementia [2], which is a condition that causes memory loss and confusion, and changes how a person acts. These symptoms of dementia occur because the reduction in blood flow means brain cells do not receive the oxygen and nutrients they require. This lack of oxygen and nutrients can cause damage to the cells, meaning they cannot carry out their normal tasks correctly. This decreased blood flow can affect the areas of the brain that have an important role in memory, called the temporal lobes. It is therefore important to understand how we can avoid decreases in brain blood flow, in order to prevent diseases like dementia. One method for keeping a steady blood flow to the brain may be to reduce our sedentary behavior.

\section{WHAT IS SEDENTARY BEHAVIOR?}

Sedentary behavior is any activity while we are awake, when we are in a sitting, reclining or lying position and using a low amount of energy. Examples include watching TV, using the computer, and sitting on a bus. Humans are becoming more and more sedentary because fewer and fewer tasks and jobs require us to be active. Research has shown that, even if we do some form of exercise during the day, if we are sedentary for the rest of our time, it can still have negative effects on our health. People who spend lots of time sedentary have increased chances of having a cardiovascular disease (a disease that affects the heart and blood vessels), diabetes (which affects the level of sugar in our blood), and even a shorter life span [3, 4]. Research tells us that high amounts of sedentary behavior may also reduce cognitive performance, which is how well a person can think and learn information [5], and may cause diseases, such as dementia [6]. Understanding how sedentary behavior affects the brain is therefore of great importance.

\section{HOW DID WE STUDY THE EFFECTS OF SEDENTARY BEHAVIOR ON THE BRAIN?}

We wanted to investigate if sitting, a sedentary behavior most of us do every day, has a negative effect on brain blood flow. We also wanted to see whether brain blood flow would change if we reduce the time we spend sitting, by getting up and taking activity breaks. 
Figure 1

Photograph of a participant having their brain blood flow assessed using transcranial Doppler ultrasound. The participant is wearing a headband around their head which is holding an ultrasound probe in front of their ear.

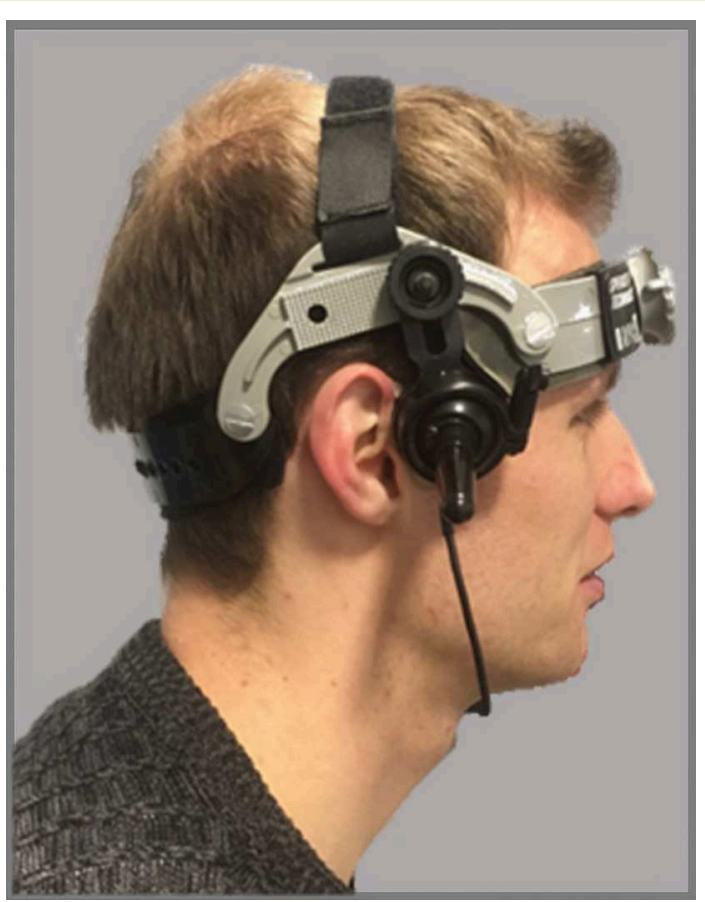

Figure 1

Fifteen adult office workers who spent a lot of time sitting took part in our study. On three separate days, our participants completed each of these conditions:

Condition A: They sat at a desk for $4 \mathrm{~h}$.

Condition B: They sat at a desk for $4 \mathrm{~h}$, but every 30 min they got up and completed a walk on a treadmill for 2 min.

Condition C: They sat at a desk for $4 \mathrm{~h}$, but after every $2 \mathrm{~h}$ they got up and completed a walk on a treadmill for 8 min.

For Conditions $\mathrm{B}$ and $\mathrm{C}$, the total amount of time our participants spent walking (16 min) was the same, however how often participants took breaks from their sitting to take a walk was different between the conditions. This allowed us to see whether the frequency of breaks (how often participants took them) or the length of the breaks had any effect on brain blood flow. While participants were sitting, they completed activities, such as reading and watching TV. Participants were not allowed to stand up or walk, except when going to the toilet.

Before and after each condition, we measured participants' brain blood flow using a piece of equipment called a transcranial Doppler ultrasound. Participants wore a headband around their heads that held two small ultrasound probes in front of their ears (Figure 1). An ultrasound probe works by sending out (emitting) sound waves, although we cannot hear these waves because they are at a too high frequency for human ears. These waves pass through the skin and 


\section{Figure 2}

How ultrasound is used to measure brain blood flow. The ultrasound probe sends out sound waves (the blue colored waves), which reflect off the blood cells flowing through the blood vessel back to the probe (the purple colored waves). The large box on the left shows a blood vessel with low blood flow. As there are only a small number of blood cells, only a few sound waves are reflected back to the probe. The large box on the right shows a blood vessel with high blood flow. As there are lots of blood cells, more sound waves are reflected back to the probe. The smaller boxes show the blood flow traces that are generated by the ultrasound probe.

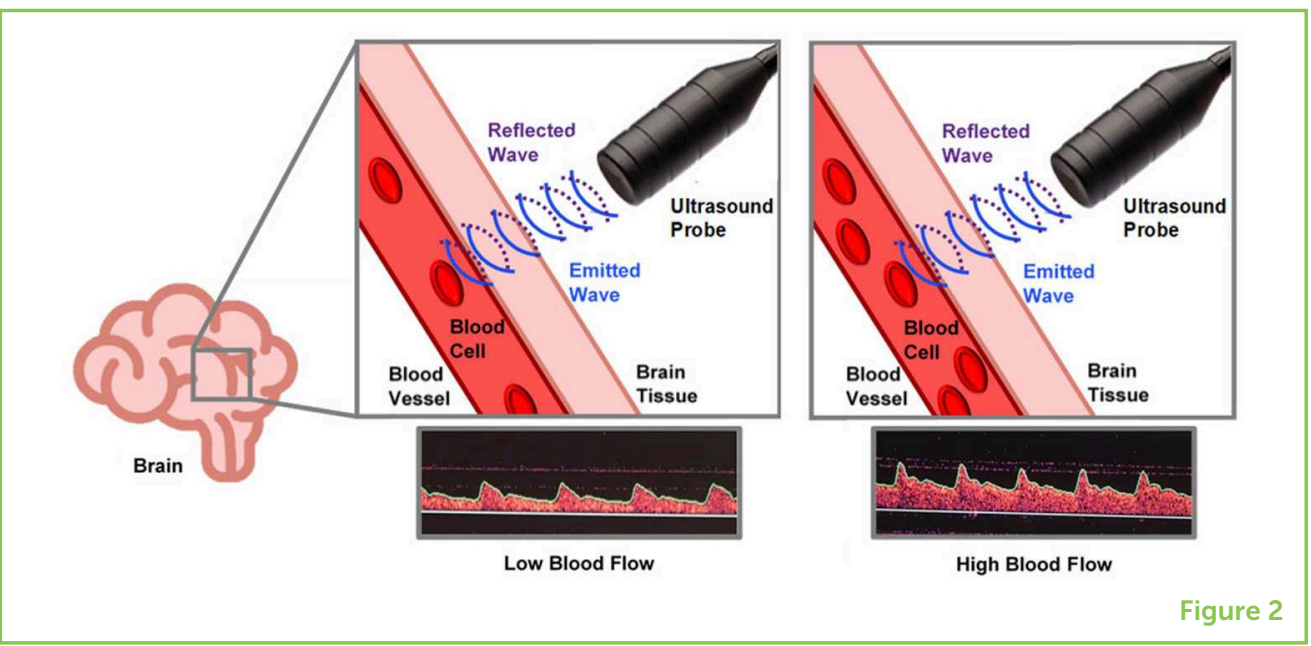

bounce off the blood cells that are in blood vessels. When the waves hit blood cells, they are then reflected back to the probe (Figure 2). The greater the blood flow through a blood vessel, the more blood cells there are, meaning more sound waves are reflected. Oppositely, if there is low blood flow through a blood vessel, there will be fewer blood cells, so fewer sound waves are reflected. Using ultrasound probes therefore allowed us to measure the blood flow through the blood vessels that deliver blood to the brain. In particular, we assessed a blood vessel called the middle cerebral artery, because this vessel delivers most (around 70-80\%) of the blood flow to the brain.

\section{SITTING AFFECTS BLOOD FLOW TO THE BRAIN}

We found that, after sitting without any breaks for $4 \mathrm{~h}$ (Condition A) there was a decrease in brain blood flow. However, when this sitting time was broken up with the short walking breaks every 30 min (Condition B), this reduction in blood flow was prevented, and instead a slight increase in blood flow was observed. In contrast, after the longer walking breaks every $2 \mathrm{~h}$ (Condition $\mathrm{C}$ ), a reduction in brain blood flow occurred. Consequently, in both conditions that included long periods of sitting (Conditions $A$ and $C$ ), brain blood flow was acutely reduced. These results suggest that sitting continuously is bad for brain blood flow, but taking regular, short breaks from sitting can help maintain blood flow. These results also tell us that, to maintain brain blood flow, breaking up sitting time often with physical activity is more important than how long these breaks last.

While our study only assessed a short time period (4h), if people are sitting for long periods each day, for example at school or at work, they may be experiencing short-term decreases in their brain blood flow every day. Over a period of years, this could lead to a long-term reduction in brain blood flow, which could cause diseases, such as dementia. The findings in our study are the starting point for helping us to understand if and how being sedentary leads to these diseases. 
More research studies need to be carried out to assess the effects of longer periods of sitting on brain blood flow to help us understand this more.

\section{CONCLUSION}

Overall, we found that prolonged sitting causes a short-term reduction in brain blood flow, but breaking up long periods of sitting by taking regular walking breaks can prevent this decrease and maintain normal blood flow to the brain. So, finding ways to help people break up their sitting often may help to maintain their brain blood flow and brain health.

\section{ORIGINAL SOURCE ARTICLE}

Carter, S. E., Draijer, R., Holder, S. M., Brown, L., Thijssen, D. H. J., and Hopkins, N. D. 2018. Regular walking breaks prevent the decline in cerebral blood flow associated with prolonged sitting. J. Appl. Physiol. 125:790-8. doi: 10.1152/japplphysiol.00310.2018

\section{REFERENCES}

1. Bertsch, K., Hagemann, D., Hermes, M., Walter, C., Khan, R., and Naumann, E. 2009. Resting cerebral blood flow, attention, and aging. Brain Res. 1267:77-88. doi: 10.1016/j.brainres.2009.02.053

2. Wolters, F. J., Zonneveld, H. I., Hofman, A., Van Der Lugt, A., Koudstaal, P. J., Vernooij, M. W., et al. 2017. Cerebral perfusion and the risk of dementia: a population-based study. Circulation 136:719-28. doi: 10.1161/CIRCULATIONAHA.117.027448

3. Wilmot, E. G., Edwardson, C. L., Achana, F. A., Davies, M. J., Gorely, T., Gray, L. J., et al. 2012. Sedentary time in adults and the association with diabetes, cardiovascular disease and death: systematic review and meta-analysis. Diabetologia 55:2895-905. doi: 10.1007/s00125-012-2677-z

4. Biswas, A., Oh, P. I., Faulkner, G. E., Bajaj, R. R., Silver, M. A., Mitchell, M. S., et al. 2015. Sedentary time and its association with risk for disease incidence, mortality, and hospitalization in adults. Ann. Intern. Med. 162:123-32. doi: 10.7326/M14-1651

5. Falck, R. S., Davis, J. C., and Liu-Ambrose, T. 2017. What is the association between sedentary behaviour and cognitive function? A systematic review. Br. J. Sports Med. 51:800-11. doi: 10.1136/bjsports-2015-095551

6. Wheeler, M. J., Dempsey, P. C., Grace, M. S., Ellis, K. A., Gardiner, P. A., Green, D. J., et al. 2017. Sedentary behavior as a risk factor for cognitive decline? A focus on the influence of glycemic control in brain health. Alzheimers Dement. (2017) 3:291-300. doi: 10.1016/j.trci.2017.04.001

SUBMITTED: 26 November 2018; ACCEPTED: 14 May 2019; PUBLISHED ONLINE: 31 May 2019. 
EDITED BY: Kelly Westlake, School of Medicine, University of Maryland, Baltimore, United States

CITATION: Carter SE, Holder SM, Thijssen DHJ and Hopkins ND (2019) Taking Regular Breaks From Sitting Prevents Reductions in Brain Blood Flow. Front. Young Minds 7:77. doi: 10.3389/frym.2019.00077

CONFLICT OF INTEREST STATEMENT: The authors declare that the research was conducted in the absence of any commercial or financial relationships that could be construed as a potential conflict of interest.

COPYRIGHT @ 2019 Carter, Holder, Thijssen and Hopkins. This is an open-access article distributed under the terms of the Creative Commons Attribution License (CC BY). The use, distribution or reproduction in other forums is permitted, provided the original author(s) and the copyright owner(s) are credited and that the original publication in this journal is cited, in accordance with accepted academic practice. No use, distribution or reproduction is permitted which does not comply with these terms.

\section{YOUNG REVIEWERS}

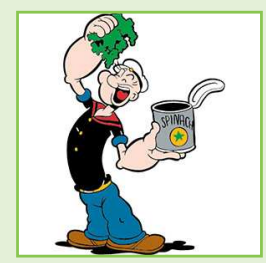

\section{ANEAL, AGE: 15}

I love to push the limits of life itself.

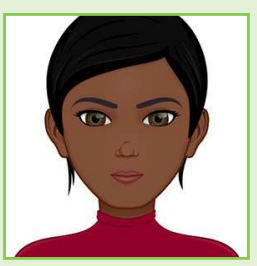

\section{JEANINE, AGE: 14}

I am a tenth grader at a very competitive school which means that I always have to be prepared for what comes next. My favorite subject is biology even though I seem to do very well in history. Also, I enjoy swimming and being on the academic team.

In addition, I make time to have lots of fun. My hobbies include, reading fantasy books, watching documentaries, hanging out with my friends, and eating my favorite foods.

\section{AUTHORS}

\section{SOPHIE E. CARTER}

Sophie is a Lecturer in Sport and Exercise who is interested in sedentary behavior (sitting) and physical activity. She investigates the influence of sedentary behavior on aspects of our health. In particular, she assesses how sitting influences cardiovascular health (our heart and blood vessels). She also studies ways in which we can reduce the amount of time people spend sitting and how this can improve individuals' health. *s.carter@yorksj.ac.uk 


\section{SOPHIE M. HOLDER}

Sophie is a Ph.D. candidate who is aiming to develop normal ranges for a test that examines the health of blood vessels (called the flow-mediated dilation test). In the future, this may allow researchers to categorize someone as being at risk for developing a cardiovascular disease.

\section{DICK H. J. THIJSSEN}

Dick is a Professor in Cardiovascular Physiology. His research aims to understand the benefits of exercise training and other non-exercise methods to improve cardiovascular (our heart and blood vessels) health and prevent people from developing cardiovascular diseases.

\section{NICOLA D. HOPKINS}

Nicola is a Lecturer in Exercise and Cardiovascular Physiology. Her research interests are focused on understanding how physical activity and sedentary behavior cause the cardiovascular system (our heart and blood vessels) to adapt. 